\title{
Topology Optimization of Disc Brake Rotor
}

\author{
Mit Patel, Vinay Khatod, Akash Patel, Nitesh Radadiya, Rajnikant Patel
}

Abstract: The main purpose of this study is to analyze the thermo-mechanical behavior of the brake disc during the braking phase. Brakes must undergo through continuous use, so many issues surround their heating characteristics when it comes to their development, including contact region properties, material choice, and development of hot spots, associated physical geometry, and deformations. The coupled thermal-structural analysis is used to determine the deformation and the Von Misses stress established in the disc to enhance performance and life of the rotor disc. A comparison between analytical calculations and results obtained from Finite Element Analysis (ANSYS) is done and the values obtained from the analysis are in the range of allowable values. The experiment has been performed with different disc-geometries. Based on the experiment results we have performed ANSYS simulation for the disc-brake. Hence best suitable optimum design is suggested based on the performance, strength and rigidity criteria.

Keywords: ANSYS, Disc Brake, FEA, Thermo-Mechanical

\section{INTRODUCTION}

A brake is a device by means of which artificial frictional resistance is applied to moving machine member, in order to stop the motion of a machine. In the process of performing this function, the brakes absorb either kinetic energy of the moving member or the potential energy given up by objects. The energy absorbed by brakes is dissipated in the form of heat. This heat is dissipated in to the surrounding atmosphere.

\section{TOPOLOGY OF ROTOR}

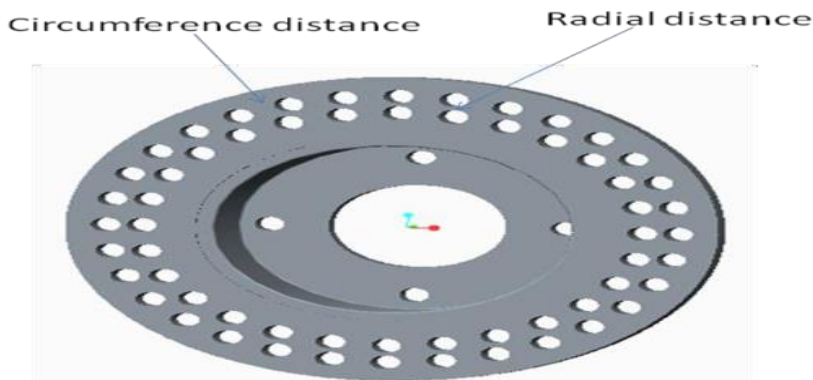

Fig. 1 Topology of Rotor

Revised Manuscript Received on December 30, 2019.

* Correspondence Author

Mit Patel, Mechanical Department, Silver Oak University, Ahmedabad, India, mitpatel.me@yahoo.com

Vinay Khatod*, Automobile Department, Ganpat University, Mehsana, India, vkhatod92@gmail.com

Akash Patel, Automobile Department, Ganpat University, Mehsana, India, abp04@ganpatuniversity.ac.in

Nitesh Radadiya, Automobile Department, Ganpat University, Mehsana, India, ndr02@ganpatuniversity.ac.in

Rajnikant Patel, Mechatronics Department, Ganpat University, Mehsana, India, rajnikant.patel@ganpatuniversity.ac.in

(C) The Authors. Published by Blue Eyes Intelligence Engineering and Sciences Publication (BEIESP). This is an open access article under the CC BY-NC-ND license (http://creativecommons.org/licenses/by-nc-nd/4.0/)
Weight optimization of rotor is possible by creating hole on surface. According to study, size and number of hole play key role for optimization. Number of hole again depend the space between two holes. So space between two holes is classified based on circumference distance and radial distance as shown in figure 1 .

\section{PARAMETRIC OPTIMIZATION}

Following possible value of hole diameter, circular distance and radial distance between two hole are selected based on geometry of gear.

\section{Table 1 Gear Geometry}

\begin{tabular}{|c|c|c|c|c|}
\hline Hole diameter (mm) & 4 & 6 & 8 & 10 \\
\hline Circular Distance between two hole & 3 & 5 & 7 & 9 \\
\hline $\begin{array}{c}\text { Radial distance between two hole } \\
\text { (mm) }\end{array}$ & 3 & 5 & 7 & 9 \\
\hline
\end{tabular}

Here we have total three parameters and four values of each parameter. So total $3^{4}=81$ solution is possible. So to reduce solution we need to go for parametric optimization by using Taguchi method in MINITAB software.

In this project 3 level and 4 factor uses in experiment and L16 orthogonal array is chosen due to its capability to check the interactions among factors. This possible array is generated by MINITAB.

Table 2 Parametric Set

\begin{tabular}{|c|c|c|c|}
\hline Set No. & Hole diameter $(\mathbf{m m})$ & DC $(\mathbf{m m})$ & DR $(\mathbf{m m})$ \\
\hline 1 & 4 & 3 & 3 \\
\hline 2 & 4 & 5 & 5 \\
\hline 3 & 4 & 7 & 7 \\
\hline 4 & 4 & 9 & 9 \\
\hline 5 & 6 & 3 & 3 \\
\hline 6 & 6 & 5 & 5 \\
\hline 7 & 6 & 7 & 7 \\
\hline 8 & 6 & 9 & 9 \\
\hline 9 & 8 & 3 & 3 \\
\hline 10 & 8 & 5 & 5 \\
\hline 11 & 8 & 7 & 7 \\
\hline 12 & 8 & 9 & 9 \\
\hline 13 & 10 & 3 & 3 \\
\hline 14 & 10 & 5 & 5 \\
\hline 15 & 10 & 7 & 7 \\
\hline 16 & 10 & 9 & 9 \\
\hline
\end{tabular}




\section{THERMO-STATIC ANALYSIS}

Apply temperature of $109 \mathrm{C}^{0}$ at surface A and convection at all surfaces of rotor as shown in below figure for transient analysis. Then Apply fixed support at four holes where rotor is fixed by means of bolt. Also apply $7152 \mathrm{~N}$ of force at both side of rotor surface and angular velocity of $123.65 \mathrm{r} / \mathrm{s}$ as boundary condition for FEA as per theoretical calculations.

Table 3 Result and Discussion of Thermo-Static Analysis

\begin{tabular}{|c|c|c|c|c|c|c|c|}
\hline 完 & 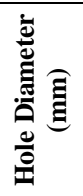 & 汱氞 & 吕高 & 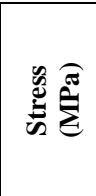 & 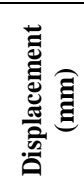 & 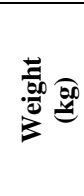 & 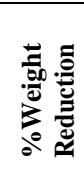 \\
\hline 1 & 4 & 3 & 3 & 43.03 & 0.136 & 2.678 & 11.6 \\
\hline 2 & 4 & 5 & 5 & 44.89 & 0.137 & 2.803 & 07.5 \\
\hline 3 & 4 & 7 & 7 & 43.65 & 0.136 & 2.847 & 06.0 \\
\hline 4 & 4 & 9 & 9 & 316.76 & 0.110 & 2.917 & 03.8 \\
\hline 5 & 6 & 3 & 3 & 41.25 & 0.137 & 2.640 & 12.9 \\
\hline 6 & 6 & 5 & 5 & 45.03 & 0.137 & 2.604 & 14.0 \\
\hline 7 & 6 & 7 & 7 & 43.42 & 0.136 & 2.775 & 08.5 \\
\hline 8 & 6 & 9 & 9 & 42.59 & 0.137 & 2.879 & 05.0 \\
\hline 9 & 8 & 3 & 3 & 38.86 & 0.136 & 2.673 & 11.07 \\
\hline 10 & 8 & 5 & 5 & 55.95 & 0.134 & 2.416 & 20.26 \\
\hline 11 & 8 & 7 & 7 & 44.24 & 0.137 & 2.760 & 08.91 \\
\hline 12 & 8 & 9 & 9 & 44.22 & 0.137 & 2.796 & 07.72 \\
\hline 13 & 10 & 3 & 3 & 322.35 & 0.110 & 2.573 & 15.08 \\
\hline 14 & 10 & 5 & 5 & 43.68 & 0.137 & 2.596 & 14.32 \\
\hline 15 & 10 & 7 & 7 & 44.86 & 0.136 & 2.658 & 12.27 \\
\hline 16 & 10 & 9 & 9 & 42.89 & 0.137 & 2.692 & 11.15 \\
\hline
\end{tabular}

\section{TAGUCHI ANALYSIS FOR STRESS}

From below graph, mean is average value for reading taken for particular parameter. From figure 2, mean value is maximum for $10 \mathrm{~mm}$ of hole diameter and minimum for 6 $\mathrm{mm}$ of hole. Mean value is maximum for $9 \mathrm{~mm}$ of circular pitch and minimum for $7 \mathrm{~mm}$ of circular pitch. Mean value is maximum for $9 \mathrm{~mm}$ of radial pitch and minimum for 7 mm of circular pitch.

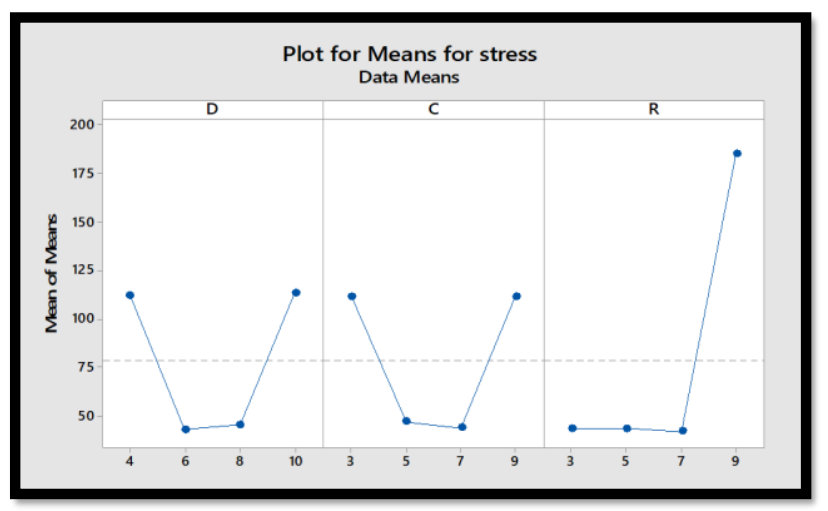

Fig. 2 Plot for Mean Stress

From figure 3, mean value of $\mathrm{S} / \mathrm{N}$ ratio is minimum for 10 $\mathrm{mm}$ of hole diameter and maximum for $6 \mathrm{~mm}$ of hole. Mean

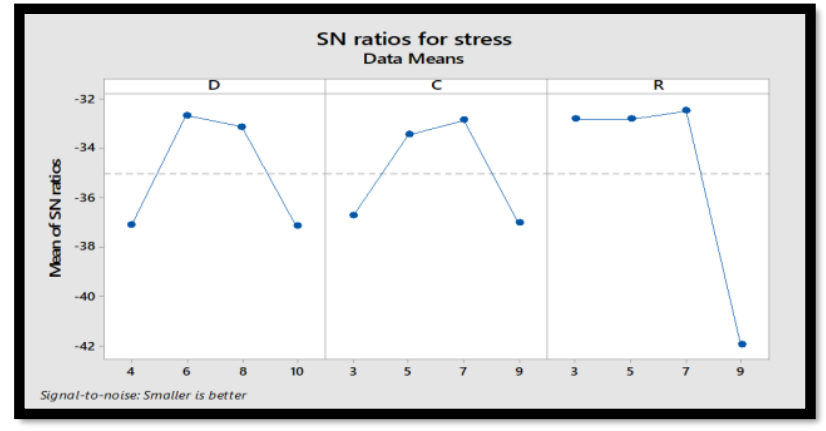

Fig. 3 Plot of S/N Ratio for Stress

value is minimum for $9 \mathrm{~mm}$ of circular pitch and maximum for $7 \mathrm{~mm}$ of circular pitch. Mean value is minimum for 9 $\mathrm{mm}$ of radial pitch and maximum for $7 \mathrm{~mm}$ of circular pitch.

\section{TAGUCHI ANALYSIS FOR WEIGHT}

From below graph, mean is average value for reading taken for particular parameter. From figure 4, mean value is maximum for $4 \mathrm{~mm}$ of hole diameter and minimum for 10 $\mathrm{mm}$ of hole diameter. Mean value is maximum for $9 \mathrm{~mm}$ of circular pitch and minimum for $5 \mathrm{~mm}$ of circular pitch. Mean value is maximum for $7 \mathrm{~mm}$ of radial pitch and minimum for $9 \mathrm{~mm}$ of circular pitch.

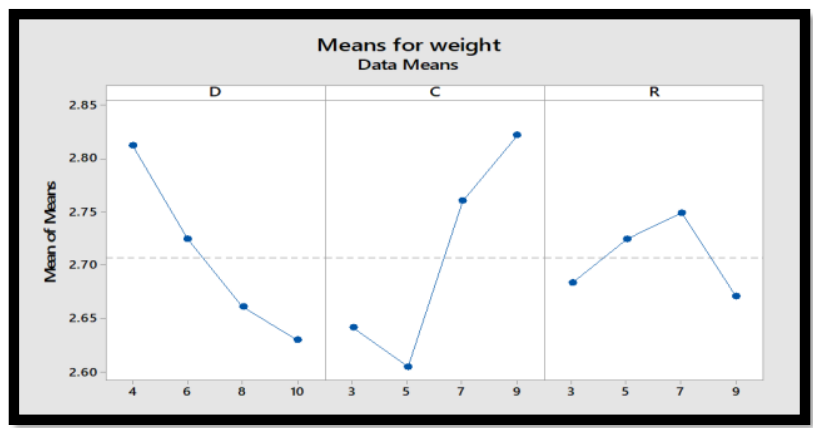

Fig. 4 Plot for Mean Weight

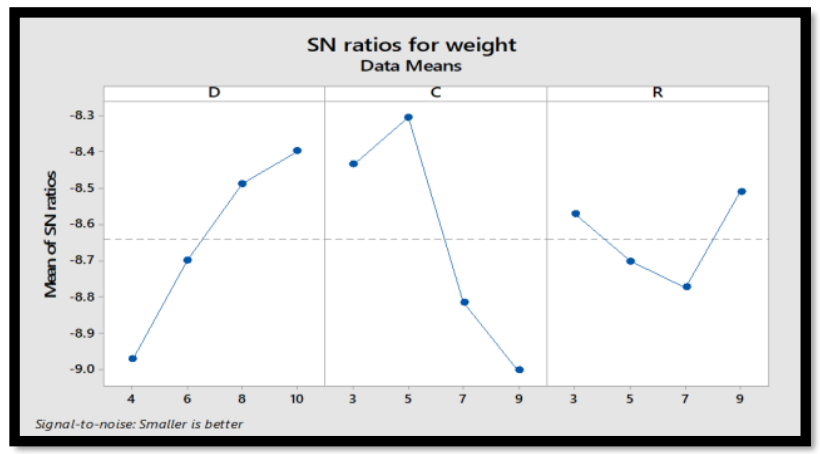

Fig. 5 Plot of S/N Ratio for Weight

From figure 5, mean value of $\mathrm{S} / \mathrm{N}$ ratio is minimum for 4 $\mathrm{mm}$ of hole diameter and maximum for $10 \mathrm{~mm}$ of hole diameter. Mean value is minimum for $9 \mathrm{~mm}$ of circular pitch and maximum for $5 \mathrm{~mm}$ of circular pitch. Mean value is minimum for $7 \mathrm{~mm}$ of radial pitch and maximum for $9 \mathrm{~mm}$ of circular pitch.

Published By: 


\section{THERMO-STATIC FEA OF OPTIMIZED SET}

Below table represent optimized parameter based on response factor of Taguchi method.

Table 4 Thermo-Static FEA of Optimized Set

\begin{tabular}{|c|c|c|c|}
\hline Set & $\begin{array}{c}\text { Diameter of hole } \\
(\mathbf{m m})\end{array}$ & Circular Pitch $\mathbf{( m m )}$ & $\begin{array}{c}\text { Radial Pitch } \\
(\mathbf{m m})\end{array}$ \\
\hline 1 & 6 & 7 & 7 \\
\hline 2 & 10 & 5 & 9 \\
\hline
\end{tabular}

Apply temperature of $109 \mathrm{C}^{0}$ at surface for 5 second and convection at all surfaces of rotor as shown in below figure for transient analysis. Then Apply fixed support at four holes where rotor is fixed by means of bolt. Also apply 7152 $\mathrm{N}$ of force at both side of rotor surface and angular velocity of $123.65 \mathrm{r} / \mathrm{s}$ as boundary conditions for FEA same as previous.

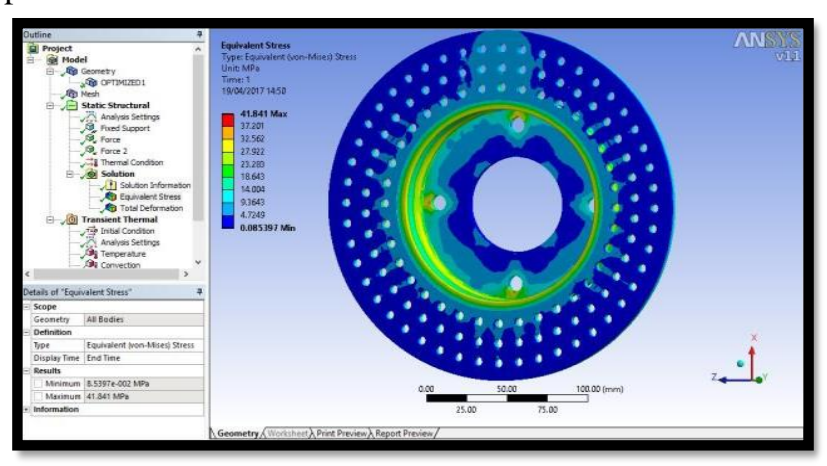

Fig. 6 Equivalent Stress for Optimized Set - 1

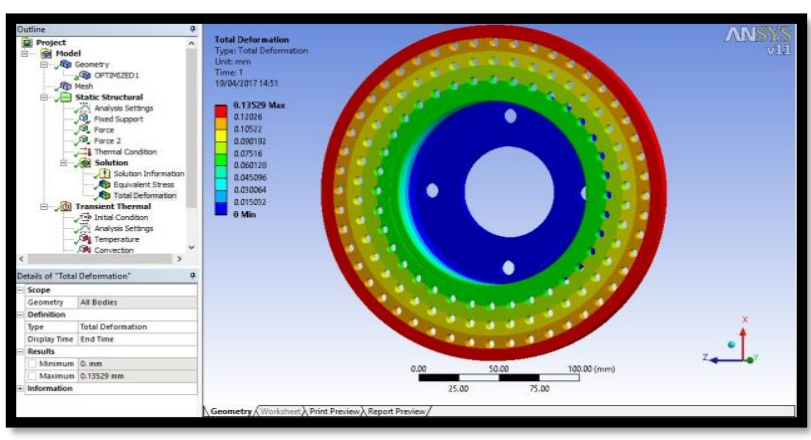

Fig. 7 Total Deflection for Optimized Set - 1

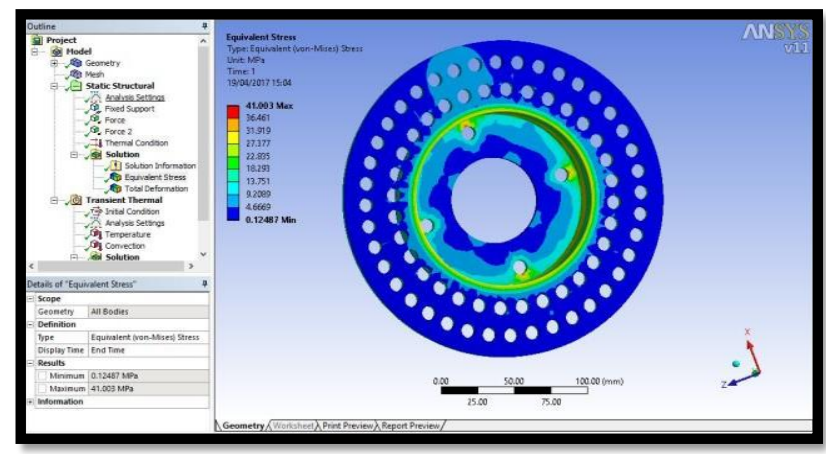

Fig. 8 Equivalent Stress for Optimized Set -2

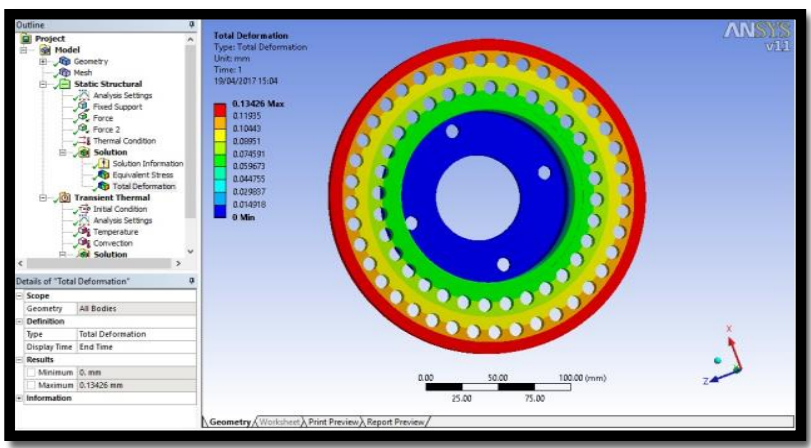

Fig. 9 Total Deflection of Optimized Set - 2

\section{RESULT AND DISCUSSION OF THERMO- STATIC ANALYSIS OF OPTIMIZED SET}

Table 5 Result and Discussion

\begin{tabular}{|c|c|c|c|c|c|c|c|}
\hline そั & 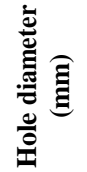 & 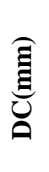 & 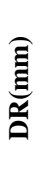 & 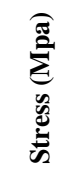 & 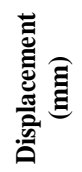 & 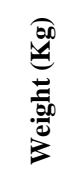 & 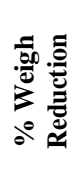 \\
\hline 1 & 6 & 7 & 7 & 41.84 & 0.135 & 2.775 & 15.84 \\
\hline 2 & 10 & 5 & 9 & 41.00 & 0.134 & 2.424 & 20.00 \\
\hline
\end{tabular}

From above result we can conclude that set 2 give best result among all previous set. Because stress and weight is minimum among all experimental set.

\section{CONCLUSION}

The analysis of thermo mechanical behavior of break disc was carried out. The Coupled thermo Structural analysis determined Von misses stress and hence the performance of life of rotor disc was calculated. Experiment wit0h different disc geometries and analysis through Ansys were compared. 18 different models are modeled by using Orthogonal Array in Taguchi method and their thermo-structural behaviors investigated. The FEA analysis is carried out and compared with Taguchi result. Among all set, $10 \mathrm{~mm}$ diameter of hole having $5 \mathrm{~mm}$ of circular pitch and $9 \mathrm{~mm}$ of radial pitch give best $20 \%$ of weight reduction.

\section{REFERENCES}

1. A.Belhocine, M.Bouchetara, Temperature and Thermal Stresses of Vehicles Gray Cast Brake, Journal of Applied Research and Technology, 11(5), 2013, 674-682

2. T. Manjunath, Dr. P. Suresh, Structural and Thermal Analysis of Rotor Disc of Disc Brake, International Journal of Innovative research in Science, Engineering and Technology, 2(12), 2013, 7741-7749

3. K. Sowjanya, S. Suresh, Structural Analysis of Disc Brake Rotor International Journal of Computer Trends and Technology, 4(7), 2013, 2295-2298

4. V. Parab, K. Naik, A. Dhale, Structural and Thermal Analysis of Brake Disc, International Journal of Engineering Development and Research, 2(2), 2014, 1398-1403

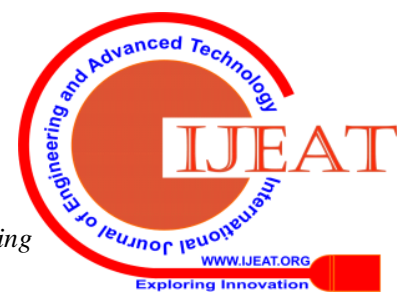


5. G. Nathi, T. Charyulu, K. Gowtham, P. Reddy, Coupled Structural / Thermal Analysis of Disc Brake,

6. International Journal of Research in Engineering and Technology, 1(4), 2012, 539-553

7. S. Abhang, D. Bhaskar, Design and Analysis of Disc Brake, International Journal of Engineering Trends and Technology, 8(4), 2014, 165-167

\section{AUTHOR'S PROFILE}

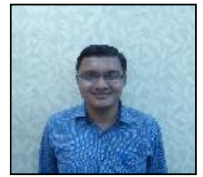

Mit Patel, Assistant Professor at Silver Oak College of Engineering and Technology. He is currently pursuing his Ph. D. in Solar Thermal Systems. He has achieved the degree of Master of Technology in Thermal Engineering and Bachelor of Engineering in Mechanical Engineering. During his tenure as an Assistant Professor, he has guided many research projects at Graduation and Post Graduation level. He has published his research papers in various National and International journals. Not only this, he has presented his research theories in number of Conferences.

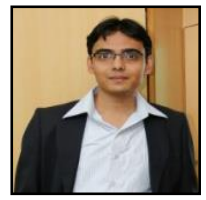

Vinay Khatod, Assistant Professor at Ganpat University achieved Bronze Medal in Master of Engineering program from Gujarat Technological University in Mechanical Engineering (I. C. Auto.). He pursued his Bachelor of Engineering in Automobile Engineering from Indus University, Ahmedabad. During his Academics he has designed and fabricated an Engine running on Alternative Fuel to Preserve Environment from Harmful Pollutants. Also, he re-modeled F-Head Engine to increase its efficiency. He has guided number of Projects at Diploma and Bachelor's Level. He has published couple of scholarly articles in National and International Journals and Conferences. He has attained number of Seminars, Conferences and Workshops for continual Development and understanding future engineering inventions.

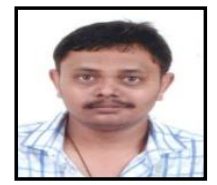

Akash Patel, Assistant Professor in Automobile Engineering Department Ganpat University, Mehsana has completed his post-graduation from Gujarat Technological University. He pursued his Bachelor of Engineering in Automobile engineering from Rajasthan Technical University, Kota. During his academic experience, he has guided number of students in Master of Engineering, Bachelor of engineering and Diploma Engineering. He has published several papers in international conferences.

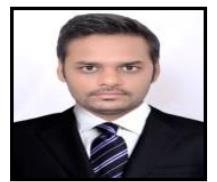

Nitesh Radadiya, Assistant Professor in Automobile Engineering Department Ganpat University, Mehsana has pursued his Bachelor of Engineering in Automobile from Gujarat University, Ahmedabad. During his Academics he has guided number of Projects at Diploma Level. He has attended number of Seminars, Conferences and Workshops for continual Development and understanding future engineering inventions. He has also arranged workshops and expert sessions on topics like Vehicle Overhauling and Vehicle Evaluation Techniques.

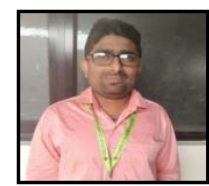

Rajnikant Patel, is employed as Assistant Professor at Ganpat University. He completed MBA in Operation Reserch from Indra Gandhi National Open University. He pursued his Bachelor of Engineering in Mechatronics Engineering from Hemchandra Acharya North Gujarat University, Patan. During his teaching period he has mentored number of mechatronics students with their projects and also arranged number of automation workshops in college to help students in their curriculum. He has also presented research papers in National and International Journals. 